Article

\title{
Visitor Mobility and Spatial Structure in a Local Urban Tourism Destination: GPS Tracking and Network Analysis
}

\author{
Koun Sugimoto*(1), Kei Ota and Shohei Suzuki \\ Department of Tourism Science, Graduate School of Urban Environment Sciences, Tokyo Metropolitan \\ University; 1-1 Minamiohsawa, Hachioji, Tokyo 192-0397, Japan; kei_ota@tmu.ac.jp (K.O.); \\ s.suzuki19900909@gmail.com (S.S.) \\ * Correspondence: koun.sugimoto@gmail.com
}

Received: 31 December 2018; Accepted: 1 February 2019; Published: 12 February 2019

\begin{abstract}
Visitor mobility is an important element for facilitating sustainable local economics and management in urban tourism destinations. Research on visitor mobility often focuses on the patterns and structures of spatial visitor behavior and the factors that influence them. This study examines the relationship between visitor mobility and urban spatial structures through an exploratory analysis of visitors' movements and characteristics, which were collected from surveys with global positional system (GPS) tracking technologies and questionnaires. The Ueno district, one of the most popular tourism destinations in Tokyo, Japan, was selected as the study area. For local stakeholders, the low accessibility levels between this district's park zone and downtown zone have become a major destination management issue. We compared visitor movements and flow networks in various places from different major trip origins (railway stations) by using several analysis techniques (GPS log distribution, spatial movement sequences, and network analysis), and examined physical and human factors that caused the different mobility patterns. The results demonstrated that physical factors, including major transport hubs (railway stations), topography, commercial accumulation, and POI distribution, affected intra-destination visitor behavior, and segmented visitor markets into different main zones. Such findings could inform future destination management policies and planning in local urban tourism destinations.
\end{abstract}

Keywords: visitor mobility; urban tourism; spatial structure; GPS tracking; network analysis; Ueno district

\section{Introduction}

Urban tourism is one of the most important world-wide forms of tourism [1]. Visitors greatly affect the environment, society, and economy of urban tourism destinations [2]. The impacts of tourism include not only positive aspects, such as economic growth, but also negative aspects, such as environmental deterioration due to human congestion and noise. For this reason, cities seek sustainable tourism management [3]. Efforts to promote sustainable tourism strive to bestow the long-term social and economic benefits of tourism upon various local stakeholders. Given that the spread of tourism consumption depends on the movement and flow of visitors, these efforts seek to distribute tourism consumption evenly within the region [4]. Moreover, many cities face the urgent problem of congestion and over-crowding stemming from the concentration of visitor flows to popular sites and access routes [5]. Therefore, understanding visitor mobility plays an essential role in developing policies to promote sustainable tourism.

Research on visitor mobility by scholars and urban planners has increased in recent years [6-11]. The main interest of such research involves visitors' movement patterns and the factors influencing 
them. Findings of such analyses can have important implications for destination planning and management, infrastructure and transport development, and impact management [12]. Scholars have conducted various empirical studies, especially on intra-destination spatial visitor behavior in urbanized areas. Such studies have involved, for instance, exploring discrete movement patterns [13,14], visualizing aggregated space consumption [5], extracting sequential movement patterns [15], comparing first-time and repeat visitors [16], analyzing specific types of visitors [6-8,17], and verifying the effects of travel preparation on on-site behavior [9].

Lau and McKercher [13] have grouped the factors considered to affect intra-destination spatial visitor behavior into three major categories: human (type of individual, travel party, motivations, etc.), physical (destination geomorphology), and time (primary or secondary destination, first-time or repeat visitor, etc.). Of these, physical factors may be the most important point for policymakers to consider regarding sustainable tourism because problems related to visitor mobility are often expected to be solved under the guise of tourism-related infrastructure and transport development. According to Lew and McKercher [12], physical factors, also called destination characteristics, include trip origins/accommodation locations, trip destinations/attraction locations, and transportation accessibility. Shoval et al. [18] examined the impact of hotel locations on spatial visitor behavior by comparing visitor space consumption across four hotels in Hong Kong, illustrating the geomorphic barriers to visitor movement. They found that visitors' behaviors were largely constrained by the limitation of distance from a hotel, though visitor activities were selective. Aranburu et al. [10] examined the relationship between visitor mobility and the centrality of tourism resources in the tourism network in the city of Bilbao and found strong relations. They also suggested that spatial configuration and accessibility played an important role in attracting visitors and contributed to the economic sustainability of urban tourism destinations.

In the technical dimension, the use of advanced tracking technologies has emerged as a novel trend in data collection and the analysis of spatial visitor behavior. Shoval and Ahas [19] reviewed such studies in tourism disciplines, noting that this type of study has increased substantially from 2005, that the most utilized technology is GPS (global positioning system) tracking, and that the geographical scale in such studies most often comprises cities. The collection of the log data from GPS tracking occurs by way of a small device embedded with GPS, such as a GPS logger and a smart phone. GPS has the advantage of recording high-resolution spatiotemporal data of individuals' positions [9], and it allows one to obtain the continuous paths visitors take [4]. Constructed spatial-rich databases of visitor movements has a lot in common with GIS (geographic information systems). Its powerful ability to analyze and visualize space and time aids greatly in uncovering and understanding visitor behavior in the virtual environment of a specific destination. Researchers frequently combine GPS and questionnaire (or interview) data to compare segmented visitors in different categories [11] and discover human factors affecting visitor movement $[6,8,9,16]$.

Various kinds of techniques have adopted GPS logs to detect and visualize patterns, including density estimation [11], grid-based aggregation [5,6], spatial movement sequence [15,20], and other relevant techniques like network analysis [10] and circular analysis [21]. Each technique has been used to extract and illustrate the static or dynamic aspects of spatial visitor behavior under specific research purposes.

Considering the state of current research as described above, the present study focuses on the relationship between visitor mobility and spatial structure of urban tourism destinations. We examine this relationship through an exploratory analysis of spatial visitor behaviors, which were recorded and collected from surveys using GPS tracking technologies and questionnaires. More specifically, we compared visitor movements and flow networks in various places from different major trip origins and examined physical and human factors that caused the different mobility patterns. The scale of destination in this study comprises "a local destination," originally defined as "the area containing the products and activities that could normally be consumed in a daytrip from the heart of the destination and that are normally promoted by the destination as part of its overall suite of 
products" [12]. We target exits of railway stations that generally constitute the major starting point of visitors' movements within cities in the metropolitan areas of Japan and same-day visitors, the largest segment of the tourist population in the area. Specifically, we selected the Ueno district in Tokyo as the study area. We thus present a novel approach to visitor mobility in cities, examining the impact of transport hub locations on spatial visitor behavior in a local destination. We also suggest future applications of the analysis, combining several techniques to analyze visitor behavior from multiple viewpoints.

In Section 2, we explain the materials and methods used, including the study area, survey, data processing techniques, and analysis. Section 3 presents the results of spatial visitor behavior through three phases of analysis: GPS log distribution, spatial movement sequences, and network analysis of visitor flows. Visitor characteristics collected from questionnaires are also provided. Section 4 discusses the factors affecting visitor mobility in terms of physical (railway station, terrain, commercial accumulation, POI distribution, etc.) and human aspects and describes implications for destination management, as well as the methodological advantages and limitations of our study. We provide our conclusions in Section 5.

\section{Materials and Methods}

\subsection{Study Area}

The Ueno district is located in the west side of Taito-ward, one of the special wards of Tokyo, Japan, which includes 23 municipalities that together make up the core part of Tokyo (Figure 1). This district mainly consists of two zone types that differ in spatial characteristics: the park zone (Ueno Park) and the downtown zone. The park zone features a wide variety of tourism resources, including both natural resources—-such as Shinobazu Pond and more than one thousand cherry blossoms-and cultural facilities—such as the Ueno Zoological Gardens and many museums, especially the Tokyo National Museum, the National Museum of Western Art (UNESCO's world cultural heritage site), the Tokyo Metropolitan Museum, and the National Science Museum. This combination of cultural and natural attractions comprises the main draw for visitors. On the other hand, the downtown zone features high commercial accumulation (Figure 1); it includes Ameyoko, the famous shopping street and some long-established shops and restaurants. According to the "Taito-ward Tourism Statistics and Marketing Survey in 2016" [22], the district received 27.3 million annual visitors. Out of these visitors, about $90 \%$ were same-day visitors, and the remaining $10 \%$ were overnight visitors. The average stay of same-day visitors was about $4 \mathrm{~h}$, and $71.2 \%$ of them tended to stay for more than $3 \mathrm{~h}$. Moreover, $83.3 \%$ were repeat visitors and $16.7 \%$ were first-time visitors.

During an interview about destination management in the Ueno district, representatives from the local tourist federation of the Ueno district and the urban planning section of Taito city government office commonly referred to the problem of low visitor mobility between the park zone and the downtown zone. The location and structure of Ueno Station, which is a major transport hub adjacent to the park zone, and the difference in elevation between the two zones (cliff line highlighted on the map on the right of Figure 1) might explain this low mobility. Most people who visit the park zone use Ueno Station when they arrive. However, more than $80 \%$ of these people do not visit the downtown zone after visiting the park zone. Moreover, overcrowding often occurs at specific places in the park zone. Thus, cultural facilities operators need to develop ways to disperse visitors to different attractions. Therefore, improving visitor movement and strengthening connections between the two zones constitute key measures in the development of sustainable destination management and local economics. 


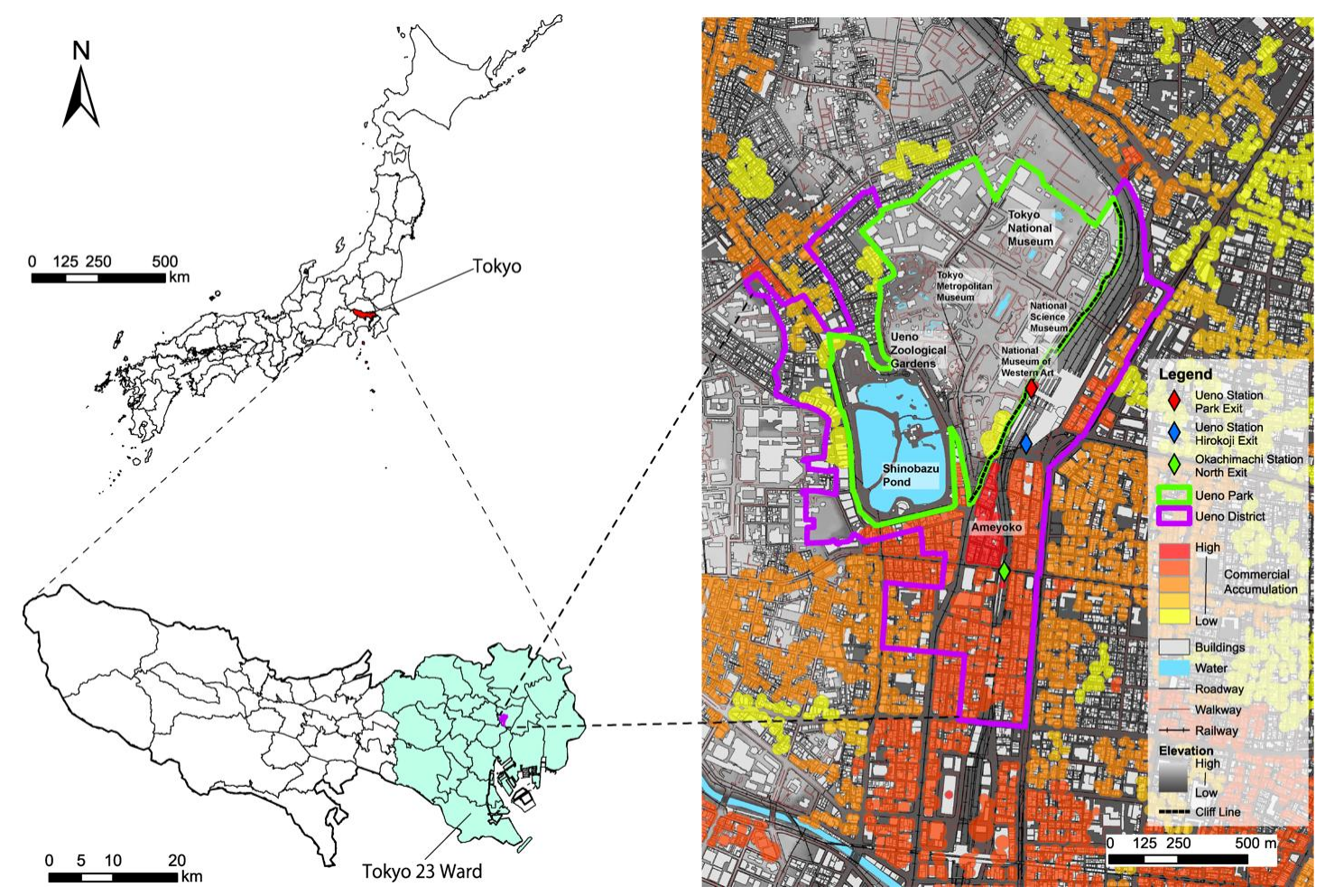

Figure 1. The location and spatial structure of the Ueno district.

\subsection{Survey and Data Collection}

Our university, in cooperation with the local government of Taito-ward, conducted visitor surveys Friday through Sunday, April 19-21, 2018. The duration of each survey day was $8 \mathrm{~h}$ (between $10 \mathrm{a}$.m. and 6 p.m.). We used a GPS logger and a questionnaire to track visitor movements and collect sociodemographic data.

To analyze the impact of major transport hubs on visitor movements, we conducted the survey at three locations (starting or ending points for visitors) on the same day. We selected these locations based on the results of pedestrian flow surveys at railway station exits in the Ueno district conducted by the urban planning sections of Taito ward and the railway company. The largest three exits in terms of pedestrian flow per day were selected as the survey locations: Ueno Station Park Exit (USPE), Ueno Station Hirokoji Exit (USHE), and Okachimachi Station North Exit (OSNE).

Research staff members approached visitors at the three locations and distributed GPS loggers to those who wished to participate in the survey. Participants were asked to return loggers the same day. Considering the possibility that visitors do not use the same station or exit at the end of their journey in the Ueno district, we gave them the option to return loggers at two other survey locations. When they arrived at either survey location, they were also asked to answer questionnaires regarding their profiles.

The GPS logger used was the Qstarz BT-Q1300S (measurement: $62 \mathrm{~mm}$ long, $38 \mathrm{~mm}$ wide, and $7 \mathrm{~mm}$ high; weight: $22 \mathrm{~g}$, Qstarz International Inc., Taiwan). We programmed the logger to identify visitor locations at 5 -second intervals. The collected sociodemographic data included age, gender, occupation, number of visits, residential area, purpose of visit, and number of companions.

A total of 155 visitors agreed to participate in the survey. Of this group, 147 viable GPS log samples wound up being suitable for analysis, while 8 samples were eliminated due to technical problems with the devices. The number of collected viable samples in each survey location was 79 at USPE, 28 at USHE, and 40 at OSNE. Acquired questionnaires comprised $81 \%$ of the total samples of loggers because $19 \%$ of participants did not agree to answer questions about their profiles. 


\subsection{Analysis}

This study compared spatial visitor behavior starting from three survey locations. In data processing and analysis, the procedure mainly consisted of: (1) the exploration of the GPS log distributions, (2) the extraction of spatial movement sequences, and (3) the construction and statistical analysis of the spatial networks of visitor flows. After these principal analyses, we generated visitor characteristics by conducting cross-tabulations to explain the relationship between visitors' behaviors and profiles.

\subsubsection{Exploring GPS Log Distributions}

First, we explored the GPS log distributions by applying three types of aggregation methods. These included the spatial distribution of GPS logs aggregated in 50-m grid cells, the change in their number at 50-m intervals from the survey location, and the circular distribution aggregated in the rose diagram [23] when each starting location was set as the cardinal point and indicates the spatial patterns of visitor space consumption in different aspects. We used ESRI's ArcGIS software (version 10.4.1, Environmental Systems Research Institute, Redlands, CA, USA) for the first aggregation method and the R (version 3.5.1) in R-Studio (version 1.2.1139, Boston, MA, USA) with the circular package for the third method.

\subsubsection{The Extraction of Spatial Movement Sequences}

The spatial movement sequence describes an ordered set of spatial positions during one movement itinerary, which can be represented simply as a series of places one person or group visits [20]. The place pattern of the movement sequence varies and generally depends on the given research purpose and a geographical scale. For instance, previous research has used originally defined points of interest (POI) [20,24], artificially divided districts [15,25], and spatial clusters of movement suspension [26]. In this study, as it was difficult to divide by a simple criterion due to the complex spatial structure of Ueno district, we adopted different criteria for each zone. We divided the park zone into 13 subzones based on the site of POI and the outline of Ueno Park, and we divided the downtown zone into 11 subzones matching the political boundaries of towns (called "chome" in Japanese) within the Taito-ward (Figure 2). Data of boundary subzones were stored in spatial databases, which can be processed in the GIS environment.

Thereafter, the tracking data were linked to the subzones. If a visitor spent more than $5 \mathrm{~min}$ within the area, we regarded it as a visit for sightseeing, shopping, eating, etc. We then extracted the combination of visited subzones for each participant and transferred the data into the spatial movement sequences database. The duration of visits in each subzone was also calculated and linked to this database. To visualize visitor movements spatially, we created the line vectors in shapefile data format from the movement sequence database, and they were visualized in three dimensions using ESRI's ArcGIS software. The Z-axis indicated the order of sequence [26], but we standardized it so that all the sequences took on values in the range of 0 to 1 . This processing aided visualization of the order in which the participants visited locations in the limited 3D space.

Based on the data of the movement sequences, we calculated the number of visited subzones for each visitor and cross-tabulated the relationship between the start and end points. 


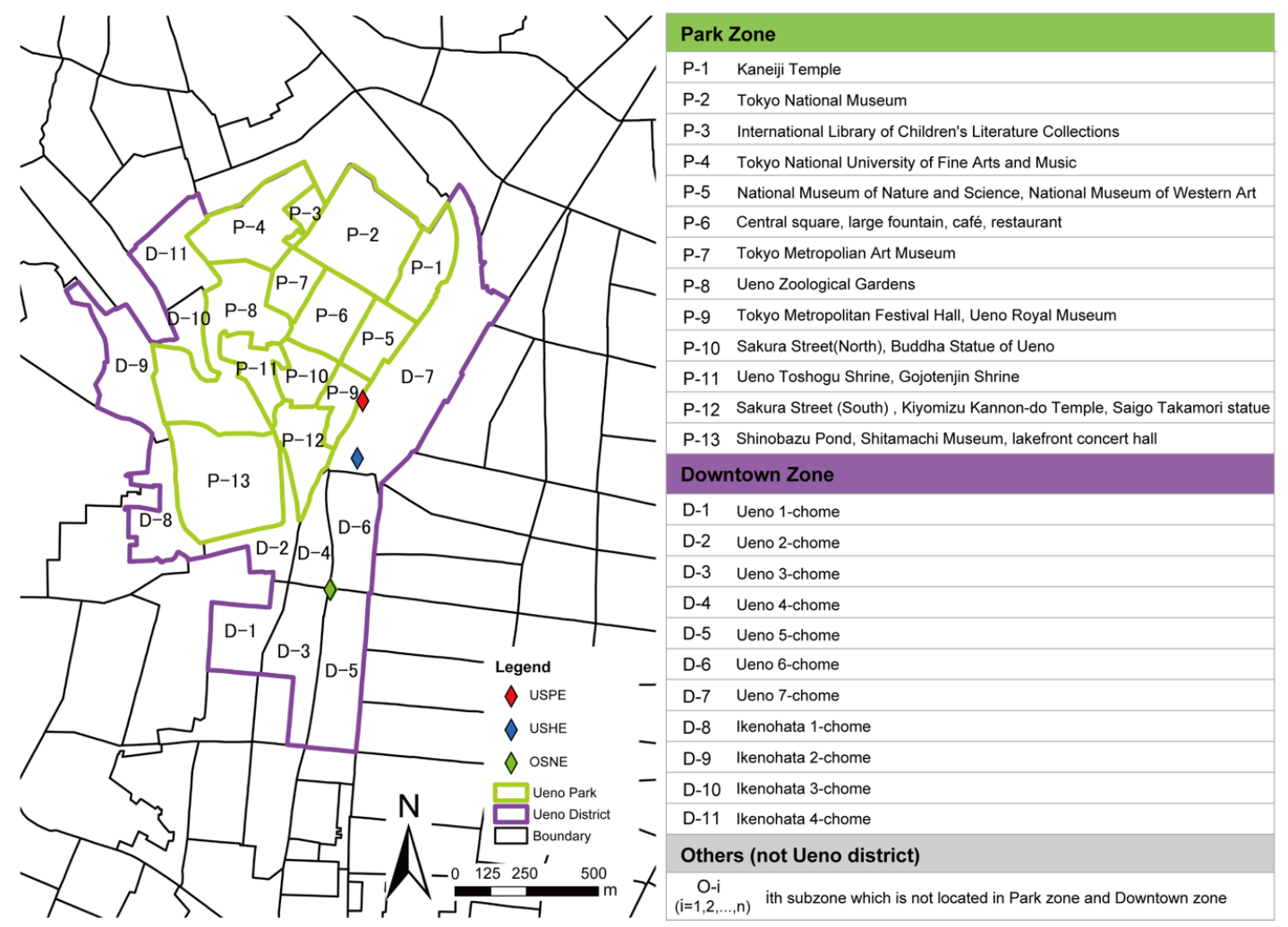

Figure 2. The map and the list of subzones.

\subsubsection{Construction and Statistical Analysis of the Spatial Network of Visitor Flows}

We constructed a spatial network of subzones based on visitor flows from the movement sequences. We then employed network analysis to explore the structural characteristics of visitor movement in the Ueno district. Interest in network analytics has increased within the tourism domain in recent years $[27,28]$, and tourist/visitor mobility is one example of an application context in the domain [28]. Network analysis, derived from graph theory, attempts to describe the structure of relations (links) between given entities (nodes), and applies quantitative analysis to produce relevant indicators and results for the study of characteristics of a whole network and the position of individuals in the network structure [29]. In this study, the subzones in which visitors stayed for over 5 min were treated as nodes and the visitor routes among subzones were treated as a series of links. Considering the movement sequence order, we regarded their relations as the directed network, which can be regarded as a functional network that indicates the actual use of the area [30,31]. From this network, we built the asymmetric matrix, where the rows and columns indicate the subzones and each cell contains the number of visitor flows between each pair of subzones. This type of matrix is also called a weighted adjacency matrix. Previous studies using network analysis in several disciplines of tourist behavior have constructed simple directed or undirected networks to analyze structure [10,29], where the cell of the weighted valued matrix is dichotomized by applying the binary data. However, considering the strength of nodes and links generates more accurate evaluations [30,31]. Therefore, we built the directed network with weights and used its version of statistical indicators.

The identification of important nodes in their network is one of the main applications of network analysis [29]. The concept of centrality is well-known as an important structural attribute within a network [32]. Various indices have been developed for measuring centrality, and these are often used in tourism-related studies $[10,29,33,34]$. We estimated three centrality indices for directed networks with weights: degree (strength), betweenness, and page rank.

The first indicator, degree centrality, is a count of the number of directed connections of a node [32] and has been used as a basic indicator of network analysis. In directed networks, degree can distinguish 
between the in-degree and out-degree of each node. When analyzing weighted networks, degree has generally been extended to the node strength induced by the sum of weights [35]. The centrality of in-strength $\left(C_{D, \text { in }}^{w}\right)$ and out-strength $\left(C_{D, \text { out }}^{w}\right)$ of a given node are defined as:

$$
C_{D, \text { in }}^{w}(i)=\sum_{j=1}^{N} w_{j i} ; C_{D, \text { out }}^{w}(i)=\sum_{j=1}^{N} w_{i j}
$$

where $w$ is the weighted adjacency matrix, thus taking a value greater than 0 if a node is connected to other nodes, and the value represents the weight of the link. $w_{j i}$ and $w_{i j}$ denote the inward and outward connections of node $i$, respectively. $N$ indicates the number of nodes within the network. The attractiveness of each subzone is measured by combining the in-strength and the mean duration of visits.

Next, betweenness centrality measures the number of shortest paths that pass through a node $[32,35]$ and indicates the accessibility of a node [10]:

$$
C_{B}^{w}(i)=\frac{g_{j k}^{w}(i)}{g_{j k}^{w}}
$$

where $g_{j k}^{w}$ is the number of shortest paths from node $j$ to node $k$, and $g_{j k}^{w}(i)$ is the number of shortest paths that contain node $i$ as an intermediary between two nodes. Thus, the betweenness centrality relies on the identification of the shortest paths. In the weighted network, the shortest path based on Dijkstra's algorithm can be defined as:

$$
d^{w}(i, j)=\min \left(\frac{1}{w_{i h}}+\ldots+\frac{1}{w_{h j}}\right)
$$

where $h$ represents an intermediary node on a path from node $i$ to node $j$ [35]. The reciprocal number of weights is used to evaluate the accessibility of nodes because the original number of weights are interpreted as the distance between two nodes. Directed networks have constraints when identifying the shortest path, as a path from one node to another can only follow the direction of a present link [35].

To compare node centrality among different networks, we needed to adopt a standard for in-strength and betweenness. Therefore, the in-strength of each node was divided by the total value, and the betweenness of each node was divided by $(N-2)(N-1)$ [36].

Finally, page rank centrality, a variant form of eigenvector centrality, was used to evaluate the influence power of nodes on surrounding nodes. Page rank was originally designed for ranking webpages by the founders of Google [37]. The basic idea behind page rank is to determine the importance of a webpage in terms of the importance assigned to the pages hyperlinking to it [38]. The page rank of node $i$ corresponds to the principal eigenvector of the links of the network and is estimated as:

$$
C_{P R}^{w}(i)=\frac{1}{\lambda} \sum_{j=1}^{N} P_{j i}^{\prime} C_{P R}^{w}(j)
$$

where $\lambda$ is a constant and $P_{j i}^{\prime}$ is the transition matrix with random reset links incorporated as follows:

$$
P_{j i}^{\prime}=d P_{j i}+(1-d) \frac{1}{N}
$$

Here, we define the transition matrix $P_{j i}$ as $\left(w_{i j} / C_{D, \text { out }}^{w}(i)\right)^{T}$. The parameter $d$ is called a dumping factor that can be set between 0 and $1 ; 0.85$ is generally used. By the random reset links incorporated, every node has at least a page rank of $(1-d) / N$. One of the reasons for this operation is to force the network to become strongly connected [39]. This extension enables the eigenvector centrality to be 
adopted in both the directed and the unconnected networks. The sum of the page ranks of all nodes within the network equals 1.

Network analysis and visualization were carried out in R-Studio with the packages igraph and visNetwork.

\section{Results}

\subsection{GPS Log Distributions}

As the result of the first analysis of spatial visitor behavior in the Ueno district, the GPS log distribution is illustrated in three different ways (Figure 3, Figure 4, and Figure 5). To complement these data, Table 1 shows the mean durations and ratio of visits in the park zone and the downtown zone. While making calculations, we targeted visitors who stayed for over $5 \mathrm{~min}$ in each zone.

Space consumption of visitors clearly differs in terms of starting location. The range of movement for visitors starting at USPE was mostly within $650 \mathrm{~m}$ and spanned west to north in orientation, which indicates that their space consumption was concentrated in the park zone. All of these visitors to the park zone stayed for an average $207.3 \mathrm{~min}$. More than half of them also visited the downtown zone $(59.5 \%)$ but the mean duration in this zone $(71.4 \mathrm{~min})$ was much lower than for the park zone.

Conversely, according to GPS logs, visitors from USHE were dispersed widely, mostly distributing within nearly $2000 \mathrm{~m}$ in a north-to-south direction. Of these visitors, $89.3 \%$ stayed somewhere within the downtown zone, and the mean duration at the downtown zone $(83.7 \mathrm{~min})$ was the highest among all three cases. Of those from USHE, $60.7 \%$ also visited the park zone, and the mean duration was $95.9 \mathrm{~min}$.

Visitors from OSNE mainly moved within the downtown zone, especially near the starting location, and they generally moved from the north-west to north. Overall, 90\% visited the downtown zone, whereas only $37.5 \%$ visited the park zone. However, the mean duration of visits in the downtown zone $(70 \mathrm{~min})$ were lower than that in the park zone (107.6 $\mathrm{min})$.

Thus, analyzing GPS log distributions provided fundamental knowledge about visitor space consumption in the targeted district, but it was limited to a static pattern. We will focus on more dynamic features of visitor movement in the next section.

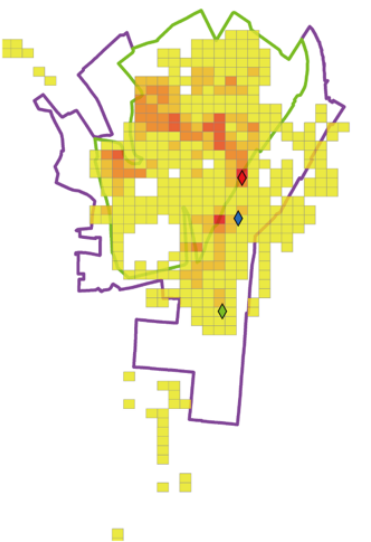

(a)

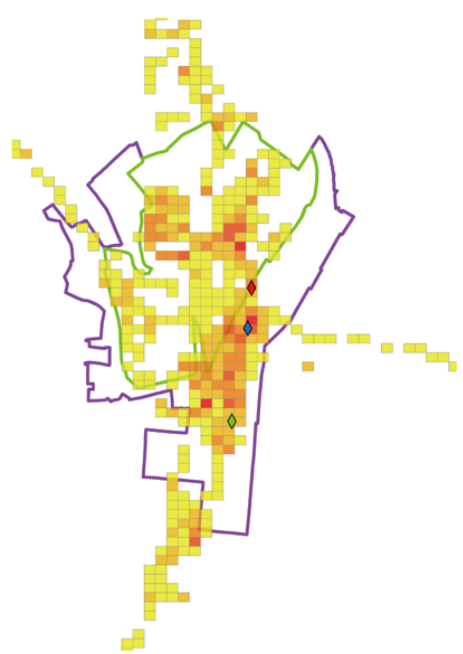

(b)

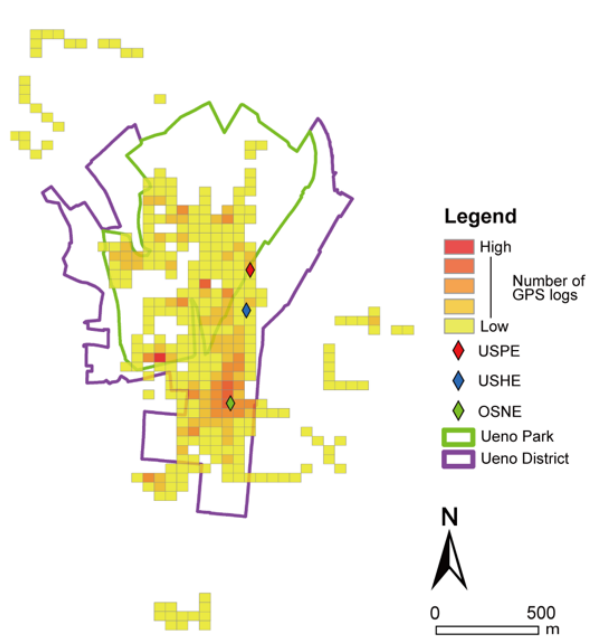

(c)

Figure 3. Distribution of GPS logs in the 50-m grid cells: (a) USPE, (b) USHE, and (c) OSNE. 


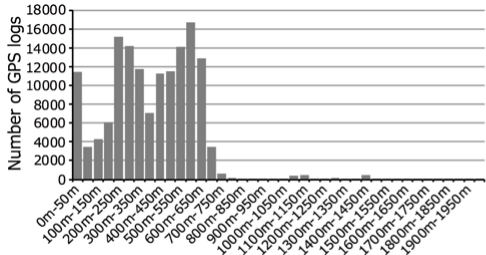

(a)

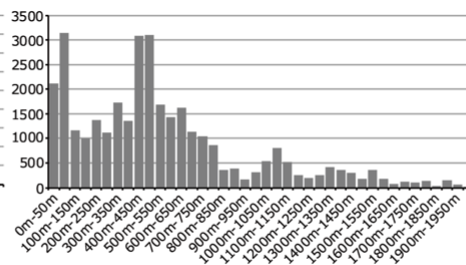

(b)

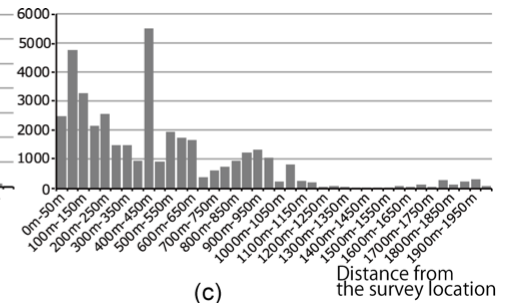

(c)

Figure 4. Changes in the accumulation of GPS logs by distance from survey locations: (a) USPE, (b) USHE, and (c) OSNE.

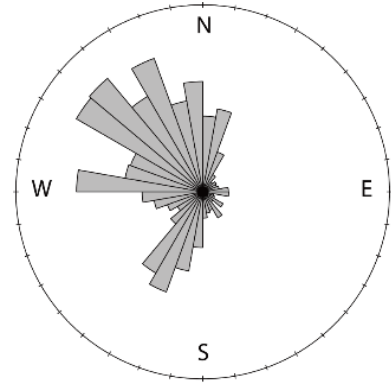

(a)

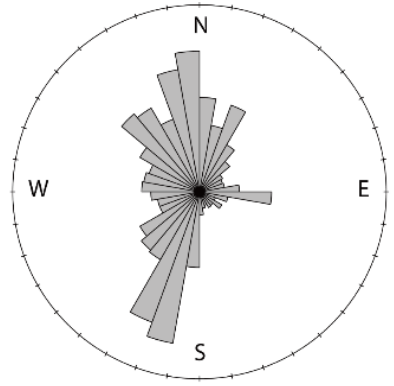

(b)

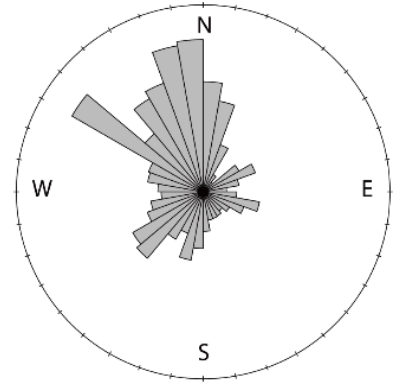

(c)

Figure 5. Distribution of GPS logs in the rose diagram: (a) USPE, (b) USHE, and (c) OSNE.

Table 1. Mean duration and ratio of visits in the two main zones.

\begin{tabular}{cccccccccc}
\hline \multirow{2}{*}{ Zone } & \multicolumn{2}{c}{ USPE } & \multicolumn{4}{c}{ USHE } & \multicolumn{3}{c}{ OSNE } \\
\cline { 2 - 10 } & $\begin{array}{c}\text { Mean Duration } \\
\text { of Visits (min) }\end{array}$ & $\mathbf{N}$ & $\%$ & $\begin{array}{c}\text { Mean Duration } \\
\text { of Visits (min) }\end{array}$ & $\mathbf{N}$ & $\%$ & $\begin{array}{c}\text { Mean Duration } \\
\text { of Visits (min) }\end{array}$ & N & $\%$ \\
\hline Park Zone & 207.3 & 78 & 98.7 & 95.9 & 17 & 60.7 & 107.6 & 15 & 37.5 \\
Downtown Zone & 71.4 & 47 & 59.5 & 83.7 & 25 & 89.3 & 70 & 36 & 90 \\
\hline
\end{tabular}

\subsection{Spatial Movement Sequences}

The spatial movement sequences of visitors, which were converted into spatial vector lines in a 3D-GIS environment, are illustrated in Figure 6. This representation helps visualize the order in which a person visits subzones and within what range a visitor moves. The number of visited subzones of each visitor and the relationship cross-tabulations between the start and end points are shown in Tables 2 and 3, respectively. In Table 2, zero indicates visits to subzones that lasted for fewer than 5 min.

Of visitors from USPE, 69.6\% visited 2, 3, or 4 subzones, and 83.5\% went back to the same survey location after sightseeing. Representative sequences, for example, are the patterns that visit cultural facilities located in Ueno Park through P-6 such as "USPE $\rightarrow \mathrm{P}-6 \rightarrow \mathrm{P}-8 \rightarrow \mathrm{P}-6 \rightarrow \mathrm{USPE}$," "USPE $\rightarrow \mathrm{P}-6 \rightarrow \mathrm{P}-2 \rightarrow \mathrm{P}-6 \rightarrow \mathrm{USPE}$," and "USPE $\rightarrow \mathrm{P}-9 \rightarrow \mathrm{P}-6 \rightarrow \mathrm{P}-8 \rightarrow \mathrm{USPE} . "$

More than $20 \%$ of visitors from USHE and OSNE spent fewer than $5 \mathrm{~min}$ in visited subzones within the Ueno district. Visitors from USPE did not evince this characteristic. On the other hand, as in the case of those from USPE, many from USHE and OSNE visited two of the subzones, and their main destinations were D-4 or D-6. About half of the visitors from USHE and OSNE returned to the same survey location, but the remaining visitors returned GPS loggers at different survey locations. 


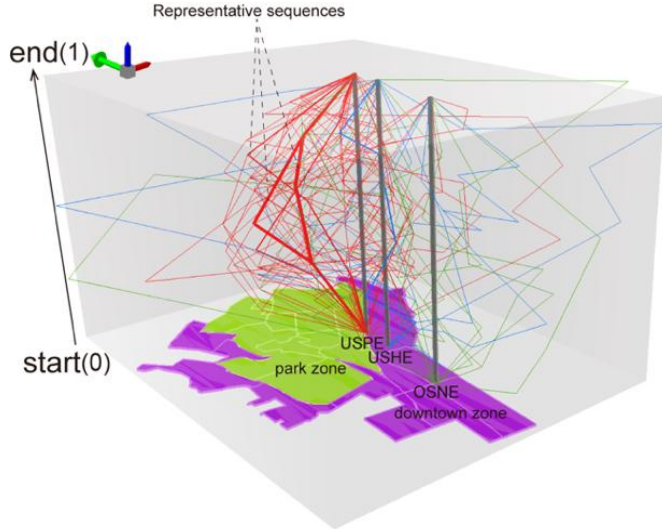

(a)

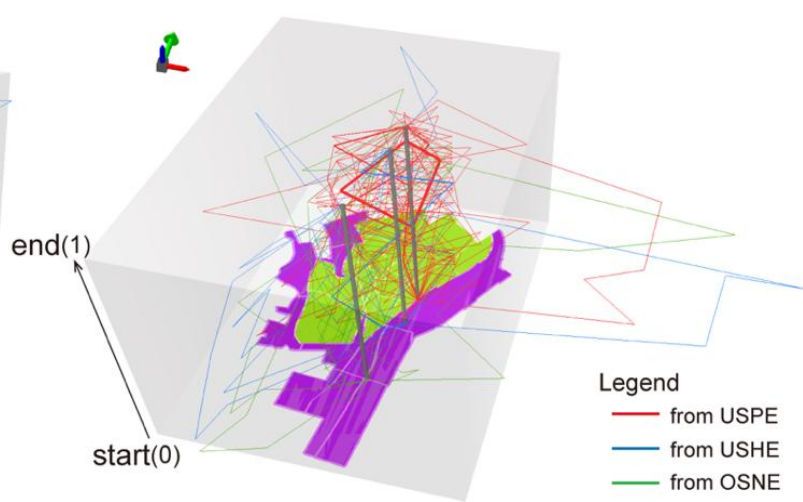

(b)

Figure 6. Spatial movement sequences represented in a 3D-GIS environment as seen from the different viewpoints; The green arrow located in the upper left of each figure denotes the north direction, Z-axis indicates the standard order of sequence, and line weight corresponds to frequency: (a) view from the southwest to northeast and (b) view from the southeast to northwest.

Table 2. Number of visited subzones.

\begin{tabular}{ccccccc}
\hline \multirow{2}{*}{$\begin{array}{c}\text { Number of Visited Subzones } \\
\text { (over 5 min for staying) }\end{array}$} & \multicolumn{2}{c}{ USPE } & \multicolumn{2}{c}{ USHE } & \multicolumn{2}{c}{ OSNE } \\
\cline { 2 - 7 } & $\mathbf{N}$ & $\mathbf{\%}$ & $\mathbf{N}$ & $\%$ & $\mathbf{N}$ & $\%$ \\
\hline 0 & 5 & 6.3 & 6 & 21.4 & 9 & 22.5 \\
1 & 5 & 6.3 & 3 & 10.7 & 2 & 5 \\
2 & 23 & 29.1 & 7 & 25 & 14 & 35 \\
3 & 15 & 19 & 3 & 10.7 & 5 & 12.5 \\
4 & 17 & 21.5 & 3 & 10.7 & 5 & 12.5 \\
5 & 9 & 11.4 & 3 & 10.7 & 4 & 10 \\
6 & 3 & 3.8 & 1 & 3.6 & 1 & 2.5 \\
$7+$ & 2 & 2.5 & 2 & 7.2 & 0 & 0 \\
\hline
\end{tabular}

Table 3. Selection of the combination between starting and end location.

\begin{tabular}{ccccccccccc}
\hline \multirow{2}{*}{ Start/End } & \multicolumn{2}{c}{ USPE } & \multicolumn{2}{c}{ USHE } & \multicolumn{2}{c}{ OSNE } & \multicolumn{2}{c}{ Other } & \multicolumn{2}{c}{ All } \\
\cline { 2 - 12 } & $\mathbf{N}$ & $\mathbf{\%}$ & $\mathbf{N}$ & $\mathbf{\%}$ & $\mathbf{N}$ & $\mathbf{\%}$ & $\mathbf{N}$ & $\mathbf{\%}$ & $\mathbf{N}$ & $\%$ \\
\hline USPE & 66 & 83.5 & 6 & 7.6 & 5 & 6.3 & 2 & 2.5 & 79 & 100 \\
USHE & 5 & 17.9 & 14 & 50 & 9 & 32.1 & 0 & 0 & 28 & 100 \\
OSNE & 10 & 25 & 8 & 20 & 22 & 55 & 0 & 0 & 40 & 100 \\
\hline
\end{tabular}

\subsection{Network Analysis of Visitor Flows}

Directed networks of visitor flows with centrality indicators, constructed based on spatial movement sequences, are illustrated in Figure 7 (in-strength) and Figure 8 (betweenness and page rank). Table 4 summarizes indicators of node centrality. These indicators can characterize subzones in terms of degree (strength), accessibility, and influence on neighbors. Moreover, Table 5 shows the mean duration of visits in each subzone. 


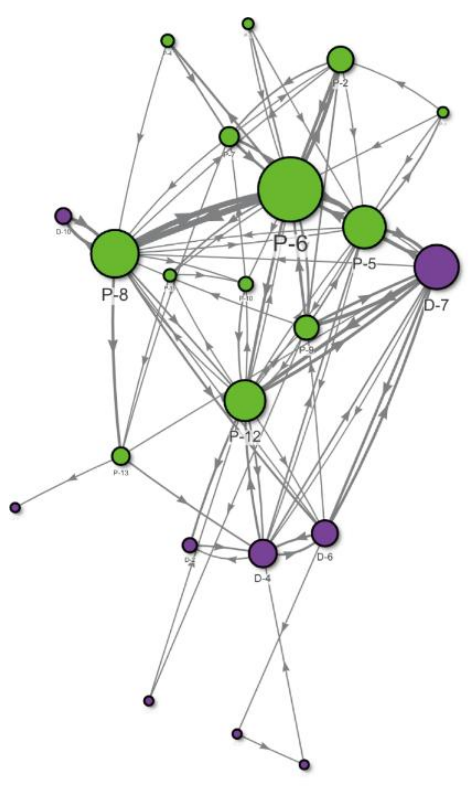

(a)

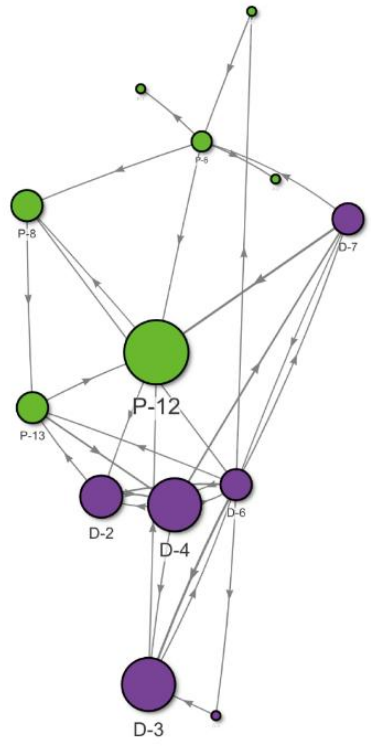

(b)

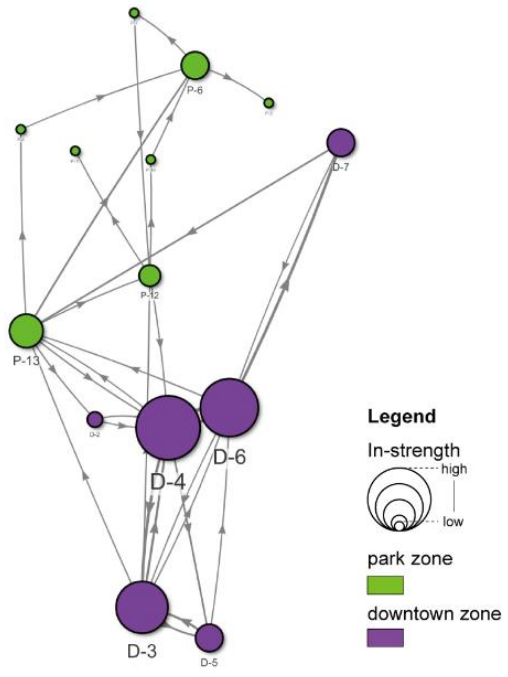

(c)

Figure 7. Visitor-flow networks with in-strength centrality: (a) USPE, (b) USHE, and (c) OSNE.

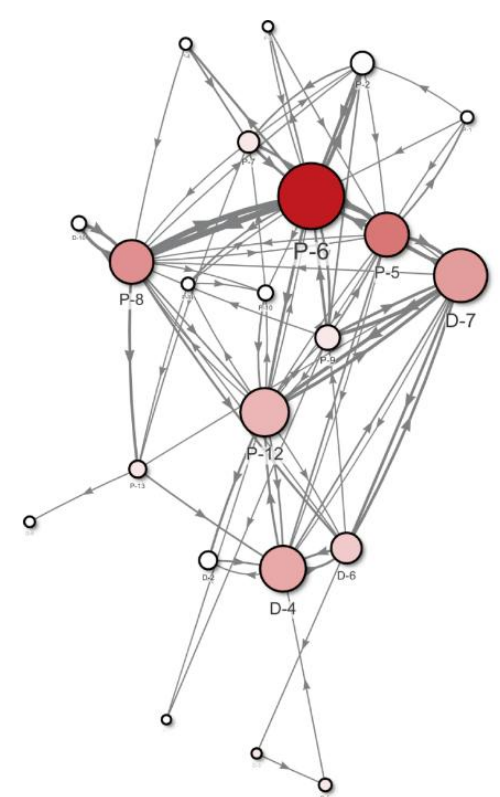

(a)

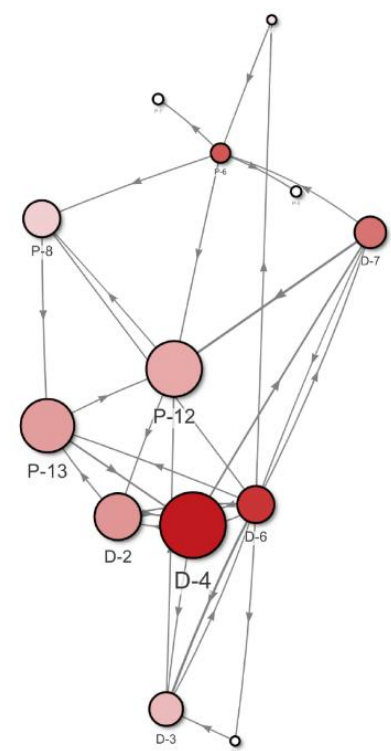

(b)

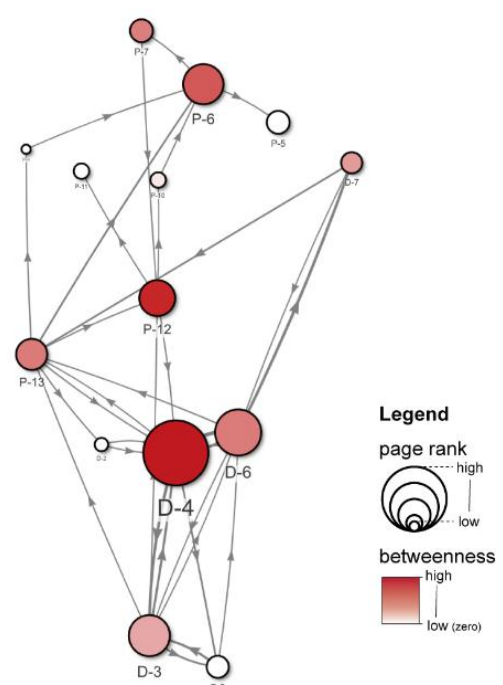

(c)

Figure 8. Visitor-flow networks with betweenness centrality and page rank centrality: (a) USPE, (b) USHE, and (c) OSNE.

In the network of visitor flows starting from USPE, the centralities were high in several subzones located in the northern part of the Ueno district. The P-6 node (central square, large fountain, café, restaurant) was largest in all centralities, but its mean duration of visits (36.2 min) was comparatively low. Therefore, P-6 was an important node in the network but its attractiveness for visitors was not very high. This was likely because P-6 is a kind of stopover connecting surrounding attractions such as P-5 and P-8. P-5 (National Museum of Nature and Science, National Museum of Western Art) and P-8 (Ueno Zoological Gardens) are high in not only three centrality measures but also mean duration of visits (126.7 $\mathrm{min}, 140.5 \mathrm{~min}$ ). This indicates that P-5 and P-8 can be regarded as substantial nodes and main attractions for visitors from USPE as well. Turning to D-7 and D-4 in the downtown zone, 
D-7 had high in-strength and page rank values because many participants starting from USPE (located in D-7) went back to Ueno Station and stayed there for more than $5 \mathrm{~min}$ to perform activities such as shopping and eating. D-4 was high in page rank and mean duration of visits (54.6 min) because it houses the famous shopping street, Ameyoko.

In the flow network of visitors from USHE, positions of high centrality were distributed between the center and south of the Ueno district. D-4 was high in three centralities, and its values for betweenness and page rank were the highest of all subzones. Therefore, D- 4 was the most accessible and influential subzone. The distribution of centralities in the network of visitors from OSNE was similar to that of visitors from USHE. D-4 was the most important node in this network structure, too.

Table 4. Summary of centrality indicators.

\begin{tabular}{|c|c|c|c|c|c|c|c|c|c|c|c|c|}
\hline & \multicolumn{4}{|c|}{ In-Strength } & \multicolumn{4}{|c|}{ Betweenness } & \multicolumn{4}{|c|}{ Page Rank } \\
\hline & $\begin{array}{l}\text { Max } \\
\text { (1st) }\end{array}$ & 2nd & 3 rd & Avg & $\begin{array}{l}\text { Max } \\
\text { (1st) }\end{array}$ & 2nd & $3 \mathrm{rd}$ & Avg & $\begin{array}{l}\text { Max } \\
\text { (1st) }\end{array}$ & 2nd & $3 \mathrm{rd}$ & Avg \\
\hline \multirow{2}{*}{ USPE } & 0.167 & 0.118 & 0.108 & 0.046 & 0.564 & 0.291 & 0.233 & 0.090 & 0.136 & 0.108 & 0.097 & 0.046 \\
\hline & P-6 & P-8 & D-7 & & P-6 & P-5 & P-8 & & P-6 & D-7 & $\mathrm{P}-12$ & \\
\hline \multirow{2}{*}{ USHE } & 0.162 & 0.135 & 0.135 & 0.079 & 0.341 & 0.269 & 0.220 & 0.120 & 0.157 & 0.133 & 0.128 & 0.077 \\
\hline & P-12 & D-3 & D-4 & & D-4 & D-6 & $P-6$ & & D-4 & $\mathrm{P}-12$ & P-13 & \\
\hline \multirow{2}{*}{ OSNE } & 0.189 & 0.170 & 0.151 & 0.073 & 0.410 & 0.346 & 0.263 & 0.139 & 0.153 & 0.111 & 0.099 & 0.071 \\
\hline & D-4 & D-6 & D-3 & & D-4 & P-12 & P-6 & & D-4 & D-6 & D-3 & \\
\hline
\end{tabular}

Table 5. Mean duration of visits in each subzone.

\begin{tabular}{|c|c|c|c|c|c|c|c|}
\hline & USPE & USHE & OSNE & & USPE & USHE & OSNE \\
\hline $\begin{array}{l}\text { Subzone } \\
\text { ID }\end{array}$ & $\begin{array}{l}\text { Mean } \\
\text { Duration of } \\
\text { Visits (min) }\end{array}$ & $\begin{array}{c}\text { Mean } \\
\text { Duration of } \\
\text { Visits (min) }\end{array}$ & $\begin{array}{c}\text { Mean } \\
\text { Duration of } \\
\text { Visits (min) }\end{array}$ & $\begin{array}{l}\text { Subzone } \\
\text { ID }\end{array}$ & $\begin{array}{c}\text { Mean } \\
\text { Duration of } \\
\text { Visits (min) }\end{array}$ & $\begin{array}{c}\text { Mean } \\
\text { Duration of } \\
\text { Visits (min) }\end{array}$ & $\begin{array}{l}\text { Mean } \\
\text { Duration of } \\
\text { Visits (min) }\end{array}$ \\
\hline \multicolumn{4}{|c|}{ Park Zone } & \multicolumn{4}{|c|}{ Downtown Zone } \\
\hline P-1 & 59.5 & & & D-1 & & 8.6 & 18.1 \\
\hline $\mathrm{P}-2$ & 109.7 & 86 & & D-2 & 41.8 & 44.7 & 25.8 \\
\hline P-3 & 73.4 & & & D-3 & 7.5 & 47.4 & 21.9 \\
\hline $\mathrm{P}-4$ & 69.9 & & & D-4 & 54.6 & 26.1 & 27 \\
\hline P-5 & 126.7 & 47.9 & 7.7 & D-5 & 13 & 12.4 & 38.4 \\
\hline P-6 & 36.2 & 35.5 & 15.3 & D-6 & 38.3 & 53.1 & 36.2 \\
\hline P-7 & 71.3 & & & D-7 & 39.7 & 26.6 & 18 \\
\hline $\mathrm{P}-8$ & 140.5 & 95.8 & & D-8 & & & \\
\hline P-9 & 23.5 & 6.9 & 24.3 & D-9 & & & \\
\hline $\mathrm{P}-10$ & 14.4 & 9 & 8.6 & D-10 & 7.5 & & \\
\hline $\mathrm{P}-11$ & 33.4 & 68.7 & & D-11 & & & \\
\hline $\mathrm{P}-12$ & 33.1 & 12.3 & 27.9 & & & & \\
\hline $\mathrm{P}-13$ & 21.4 & 25.9 & 72 & & & & \\
\hline
\end{tabular}

\subsection{Visitor Characteristics}

To examine human factors, we compared visitor characteristics across the three survey locations (Table 6). This information helped us understand the transport hub selection and subsequent intra-destination visitor movement. Most visitors live in the Tokyo metropolitan area, where they can access the Ueno district easily by train. Fisher's exact test results revealed significant differences in age, occupation, visit experience, purpose, and number of persons in a group, but there was a similar tendency in visitors from USHE and OSNE. Notable features of visitors from USPE included being under 29 years old, students, first-time and light-repeat visitors, sightseeing purpose, and being part of a group of 2-3 people, whereas those for visitors from USHE and OSNE included being between 30 and 59 years old, heavy-repeat visitors (more than 50 times), shopping and gourmet food, and not being part of a group. 
Table 6. Visitor characteristics.

\begin{tabular}{|c|c|c|c|c|c|c|c|c|}
\hline \multirow{2}{*}{ Category } & \multirow{2}{*}{ Item } & \multicolumn{2}{|c|}{ USPE } & \multicolumn{2}{|c|}{ USHE } & \multicolumn{2}{|c|}{ OSNE } & \multirow{2}{*}{$\begin{array}{l}\text { Fisher's Exact } \\
\text { Test: } p \text {-value }\end{array}$} \\
\hline & & $\mathbf{N}$ & $\%$ & $\mathbf{N}$ & $\%$ & $\mathbf{N}$ & $\%$ & \\
\hline \multirow{3}{*}{ Age } & Under 29 & 32 & 52.5 & 8 & 32 & 5 & 15.2 & \multirow{3}{*}{0.00} \\
\hline & $30-59$ & 23 & 37.7 & 13 & 52 & 19 & 57.6 & \\
\hline & Over 60 & 6 & 9.8 & 4 & 16 & 9 & 27.3 & \\
\hline \multirow{2}{*}{ Sex } & Man & 22 & 36.1 & 14 & 56 & 14 & 42.4 & \multirow{2}{*}{0.25} \\
\hline & Woman & 39 & 63.9 & 11 & 44 & 19 & 57.6 & \\
\hline \multirow{4}{*}{ Occupation } & Worker & 31 & 50.8 & 18 & 72 & 17 & 53.1 & \multirow{4}{*}{0.04} \\
\hline & Student & 20 & 32.8 & 2 & 8 & 4 & 12.5 & \\
\hline & House wife & 5 & 8.2 & 2 & 8 & 8 & 25 & \\
\hline & Other & 5 & 8.2 & 3 & 12 & 3 & 9.4 & \\
\hline \multirow{3}{*}{ Residential area } & Tokyo & & & & & & & \multirow{3}{*}{0.80} \\
\hline & Metropolitan & 48 & 76.2 & 21 & 84 & 26 & 78.8 & \\
\hline & Other & 15 & 23.8 & 4 & 16 & 7 & 21.2 & \\
\hline \multirow{4}{*}{ Visit experience } & First & 11 & 18 & 0 & 0 & 1 & 3 & \multirow{4}{*}{0.00} \\
\hline & $2-9$ & 22 & 36.1 & 4 & 16 & 6 & 18.2 & \\
\hline & $10-49$ & 18 & 29.5 & 7 & 28 & 13 & 39.4 & \\
\hline & $50+$ & 10 & 16.4 & 14 & 56 & 13 & 39.4 & \\
\hline \multirow{5}{*}{ Purpose } & Sightseeing & 58 & 60.4 & 6 & 13 & 12 & 18.8 & \multirow{5}{*}{0.00} \\
\hline & Shopping & 5 & 5.2 & 9 & 19.6 & 16 & 25 & \\
\hline & Gourmet food & 10 & 10.4 & 11 & 23.9 & 15 & 23.4 & \\
\hline & Wandering & 20 & 20.8 & 17 & 37 & 16 & 25 & \\
\hline & Other & 3 & 3.1 & 3 & 6.5 & 5 & 7.8 & \\
\hline \multirow{4}{*}{$\begin{array}{l}\text { Number of persons } \\
\text { in a group }\end{array}$} & 1 & 3 & 4.9 & 13 & 54.2 & 14 & 42.4 & \multirow{4}{*}{0.00} \\
\hline & 2 & 33 & 54.1 & 6 & 25 & 12 & 36.4 & \\
\hline & $3-6$ & 21 & 34.4 & 5 & 20.8 & 7 & 21.2 & \\
\hline & 7 & 5 & 8.2 & 0 & 0 & 0 & 0 & \\
\hline
\end{tabular}

\section{Discussion}

\subsection{Visitor Mobility and Urban Spatial Structure}

Comparing the three cases, we found that visitors starting from USPE tended to visit 2-4 subzones located in the park zone and return to the same survey location after sightseeing. In contrast, those from USHE and OSNE spent most of their visit at commercial areas in the downtown zone, and about half of them selected a different endpoint. Moreover, the network structure and node centralities clearly differed though all visitors spent time within the Ueno district. For the flow network of visitors from USPE, several node centralities in the north of the Ueno district had high values, especially in P-5, P-6, P-8, and D-7. The other two cases had high centrality values from the center to the southern parts of the subzones. D-4 proved an important node for visitors from both USHE and OSNE, and it scored the highest in all centralities in the network starting from OSNE.

These results show that urban spatial structure strongly impacts visitor movements. In particular, complex regional factors, such as the exit locations of railway stations, the cliff line, the spatial arrangement of POIs, and the commercial accumulation pattern, constrained (or induced) visitors' spatial behavior. For example, D-4 was connected by major roads and was located between USHE and OSNE, and it had the highest commercial accumulation. Its easy access and attractiveness made D-4 the most important node in the flow network of visitors from USHE and OSNE. The cliff line may also be a barrier for almost all visitors, preventing movement between the two main zones.

Visitor movement results can be explained in part by theories of human mobility. Shoval et al. [18] examined the impact of hotel location to visitor movement and found the distance decay effect in the change of time budgeted according to the distance from hotels (starting location). The results in Sections 3.1 and 3.3 demonstrate the distance decay of visitors from USHE and OSNE; they mainly visited places near railway stations and spent a lot of time there. This was due to the distance limitations of pedestrians related to the strength and endurance required by walking [12]. On the other 
hand, time spent by visitors from USPE was concentrated at specific tourist attractions such as the zoo and museums. In this case, visitor time spent was strongly constrained by the attractiveness and configurations of facilities.

Depending on whether the main POIs were located within the park zone or the downtown zone, visitor characteristics differed significantly. In the park zone, visitors tended to be first-timers or light repeaters sightseeing at the cultural facilities. In the downtown zone, visitors consisted mainly of heavy repeaters who visited the Ueno district to shop and eat at gourmet restaurants. The current market for each zone has been clearly segmented by the urban spatial structure. The reason for this may be that the commercial areas in the downtown zone not only offer famous tourist spots but also feature a wide variety of shops, which can serve various activities including needs related to visitors' daily lives. By contrast, Ueno Park offers a comparatively limited number of activities.

Thus, we confirmed that human factors, such as experience as a visitor, also affected visitor mobility in the Ueno district. Previous research has reported the difference between first-timers and repeaters [16]. However, the results of this study suggest that degrees of experience, such as light-repeating or heavy-repeating, should be considered in the case of urban tourism destinations that urban residents can access freely.

\subsection{Management Implication}

Visitor mobility is an important element of sustainable local economics and management in urban tourism destinations. In the Ueno district, low levels of accessibility between the park zone and the downtown zone has become a major issue of destination management in the eyes of local stakeholders. Our study's results divided visitors to the Ueno district into the park-oriented and the downtown-oriented. Although the more than 25 million people who visit the park zone each year represent a high potential market for commercial areas, they can only access the downtown zone through adjacent subzones such as D-4 and D-7. To improve visitor mobility and inter-zone accessibility, it may be necessary to introduce an effective promotional campaign covering all areas within the Ueno district. However, changing visitor movements is not an easy task. It may be impossible to solve the fundamental problem only through tourism policies dealing with intangible factors. Modification of infrastructure that can help redesign visitor movements should also be considered in crafting policies on urban development and tourism.

\subsection{Methodological Advantage and Limitation}

We proposed three phases of data processing and analysis to explore visitors' spatial behaviors and examined differences in visitor movement according to starting locations. Visualizing GPS log distributions revealed static patterns of visitor space consumption. Spatial movement sequences and visitor flow networks effectively elucidated dynamic aspects of visitor movements. Applying network analysis to visitor flows enabled us to clarify the characteristics of network structure and identify the important subzones in terms of degree(strength), accessibility, and influence on neighbors. Moreover, comparative analysis of several networks revealed that visitor mobility and node centrality differed depending on the situation of visitors. The computation of node centralities based on directed networks with weights reflected actual visitor flows and spatial interaction among nodes more precisely than previous research, which had used non-weighted and undirected networks for analyzing visitor mobility in a specific city, had done [10]. Thus, this study demonstrates the effectiveness and new applicability of network analysis for spatial behavior studies.

A more extensive approach for our proposed method could promote a better understanding of the visitor mobility in a local urban tourism destination. For instance, Taczanowska et al. [30,31] proposed that comparing the functional network (directed network constructed from visitor movement data) and the structural network (undirected network constructed based on road networks) could be useful for evaluating natural recreational spaces and developed some important implications for management 
from the difference between these two types of networks. Applying such analyses to cities and the use of directed networks with weights to functional network construction will be a challenge in the future.

A limited sample size, especially for visitors from USHE, and a restricted number of days for the period of investigation might have hindered our ability to derive general trends in visitor behavior within the Ueno district. However, administering the survey at several locations on the same day enabled us to conduct a comparative analysis of visitor movements starting from different transport hubs and derive useful findings with management implications.

Finally, it was difficult to adopt a quantitative analysis methodology to explore the relationship between visitor movement and its spatial factors due to site complexity. However, we could confirm the impact of major transport hubs on visitor movements with the quantitative analysis. Moreover, the highest centrality for the network of visitors from USHE and OSNE (subzone D-4) corresponded to the highest commercial accumulation (subzone D-4). The effects of the other spatial factors were derived by comparing the map of the spatial structure and the visualized results of visitor movement analysis. The quantification and systematic analysis for understanding the relationship between visitor movement and destination spatial structures will also be the focus of future research.

\section{Conclusions}

This study examined the relationship between visitor mobility and urban spatial structure by comparing spatial visitor behavior from three different trip origins in the Ueno district. Combining several analysis techniques (GPS log distribution, spatial movement sequences, and network analysis), we explored the static and dynamic aspects of visitor behavior. Moreover, network analysis helped us evaluate the importance of each subzone from the network of visitor flows and allowed us to understand visitor mobility in relation to the spatial structure of the targeted area. Such analytical methods are applicable to other local destinations. The results demonstrated that physical factors, including major transport hubs (railway stations), topography, commercial accumulation, and POI distribution, affected intra-destination visitor behavior and segmented the markets into different main zones. These findings might inform policies designed for destination management and planning in the Ueno district. We hope that our study will stimulate the local tourist federation and government to make better decisions and implement rational schemes to foster sustainable tourism in the future.

Author Contributions: K.S. and K.O. designed the research and identified the logical connections of the arguments and counter-arguments; All authors collected the data; K.S. organized and analyzed the data; K.S. wrote the paper. All authors read and approved the final manuscript.

Funding: This research was supported by the consigned research funding we received from the urban planning section at the Taito city government office.

Acknowledgments: We would like to pay our special thanks to persons in charge of the urban planning section at the Taito city government office for aiding our work and negotiating with local stakeholders for the survey. We received generous support from Professor Kikuchi and the members of Research Administration Office in the Organization for Research Promotion in TMU. Finally, we would like to thank the university students who cooperated with us as research staff members and the people who participated in the Ueno district. A part of this research was the result of the joint research with CSIS, the University of Tokyo (No. 675) and used the following data: Zmap-TOWNII provided by ZENRIN CO., LTD and Commercial Accumulation Statistics provided by Micro Geo Data Forum of Japan.

Conflicts of Interest: The authors declare no conflict of interest. The funders played no role in the design of the study; in the collection, analyses, or interpretation of data; in the writing of the manuscript; or in the decision to publish the results.

\section{References}

1. Ashworth, G.; Page, S.J. Urban tourism research: Recent progress and current paradoxes. Tour. Manag. 2011, 32, 1-15. [CrossRef]

2. Wise, N. Outlining triple bottom line contexts in urban tourism regeneration. Cities 2016, 53, 30-34. [CrossRef]

3. Zamfir, A.; Corbos, R.A. Towards sustainable tourism development in urban areas: Case study on Bucharest as tourist destination. Sustainability 2015, 7, 12709-12722. [CrossRef] 
4. Edwards, D.; Griffin, T. Understanding tourists' spatial behaviour: GPS tracking as an aid to sustainable destination management. J. Sustain. Tour. 2013, 21, 580-595. [CrossRef]

5. Shoval, N. Tracking technologies and urban analysis. Cities 2008, 25, 21-28. [CrossRef]

6. De Cantis, S.; Ferrante, M.; Kahani, A.; Shoval, N. Cruise passengers' behavior at the destination: Investigation using GPS technology. Tour. Manag. 2016, 52, 133-150. [CrossRef]

7. Nishimura, K.; Sugimoto, K.; Kikuchi, T. Visitor movement patterns in the context of community cycle system for holiday use: A case study in Kawagoe city, Saitama prefecture. Tour. Stud. 2018, 29, $29-42$. (In Japanese with English Abstract).

8. Sugimoto, K. Intra-destination visitor movement during a local tourist event: A case study on a festival in Ueno Park, Tokyo. Tour. Stud. 2017, 29, 17-28, (In Japanese with English Abstract).

9. Bauder, M.; Freytag, T. Visitor mobility in the city and the effects of travel preparation. Tour. Geogr. 2015, 17, 682-700. [CrossRef]

10. Aranburu, I.; Plaza, B.; Esteban, M. Sustainable cultural tourism in urban destinations: Does space matter? Sustainability 2016, 8, 699. [CrossRef]

11. East, D.; Osborne, P.; Kemp, S.; Woodfine, T. Combining GPS \& survey data improves understanding of visitor behaviour. Tour. Manag. 2017, 61, 307-320.

12. Lew, A.; McKercher, B. Modeling tourist movements: A local destination analysis. Ann. Tour. Res. 2006, 33, 403-423. [CrossRef]

13. Lau, G.; McKercher, B. Understanding tourist movement patterns in a destination: A GIS approach. Tour. Hosp. Res. 2006, 7, 39-49. [CrossRef]

14. Mckercher, B.; Lau, G. Movement patterns of tourists within a destination. Tour. Geogr. 2008, 10, 355-374. [CrossRef]

15. Shoval, N.; Isaacson, M. Sequence alignment as a method for human activity analysis in space and time. Ann. Assoc. Am. Geogr. 2007, 97, 282-297. [CrossRef]

16. McKercher, B.; Shoval, N.; Ng, E.; Birenboim, A. First and repeat visitor behaviour: GPS tracking and GIS analysis in Hong Kong. Tour. Geogr. 2012, 14, 147-161. [CrossRef]

17. Pettersson, R.; Zillinger, M. Time and space in event behavior: Tracking visitors by GPS. Tour. Geogr. 2011, 13, 1-20. [CrossRef]

18. Shoval, N.; McKercher, B.; Ng, E.; Birenboim, A. Hotel location and tourist activity in cities. Ann. Tour. Res. 2011, 38, 1594-1612. [CrossRef]

19. Shoval, N.; Ahas, R. The use of tracking technologies in tourism research: The first decade. Tour. Geogr. 2016, 18, 587-606. [CrossRef]

20. Xia, J.; Ciesielski, V.; Arrowsmith, C. Data mining of tourists spatio-temporal movement patterns: A case study on Phillip Island. In Proceedings of the Eighth International Conference on Geocomputation, Ann Arbor, MI, USA, 31 July-3 August 2005; pp. 1-15.

21. Chhetri, P.; Corcoran, J.; Arrowsmith, C. Investigating the temporal dynamics of tourist movement: An application of circular statistics. Tour. Anal. 2010, 15, 71-88. [CrossRef]

22. Taito Tourism Statistics and Marketing Survey in 2016 (Summary Version). Available online: https:/ / www.city.taito.lg.jp/index/bunka_kanko/yukyaku/tyousatoukei/marketing/28kankotokei. files/1gaiyouban.pdf (accessed on 30 December 2018).

23. Fisher, N.I. Statistical Analysis of Circular Data; Cambridge University Press: Cambridge, UK, 1995.

24. Xia, J.C.; Zeephongsekul, P.; Packer, D. Spatial and temporal modelling of tourist movements using Semi-Markov processes. Tour. Manag. 2011, 32, 844-851. [CrossRef]

25. Huang, X.-T.; Wu, B.-H. Intra-attraction tourist spatial-temporal behaviour patterns. Tour. Geogr. 2012, 14, 625-645.

26. Orellana, D.; Bregt, A.K.; Ligtenberg, A.; Wachowicz, M. Exploring visitor movement patterns in natural recreational areas. Tour. Manag. 2012, 33, 672-682. [CrossRef]

27. Scott, N.; Baggio, R.; Cooper, C. Network Analysis and Tourism: From Theory to Practice; Channel View Publications: Bristol, UK, 2008.

28. Baggio, R. Network science and tourism-The state of the art. Tourim Rev. 2017, 72, 120-131. [CrossRef]

29. Shih, H.Y. Network characteristics of drive tourism destinations: An application of network analysis in tourism. Tour. Manag. 2006, 27, 1029-1039. [CrossRef] 
30. Taczanowska, K.; González, L.M.; Garcia-Massó, X.; Muhar, A.; Brandenburg, C.; Toca-Herrera, J.L. Evaluating the structure and use of hiking trails in recreational areas using a mixed GPS tracking and graph theory approach. Appl. Geogr. 2014, 55, 184-192. [CrossRef]

31. Taczanowska, K.; Bielański, M.; Gonzalez, L.M.; Garcia-Massó, X.; Toca-Herrera, J.L. Analyzing spatial behavior of backcountry skiers in mountain protected areas combining GPS tracking and graph theory. Symmetry 2017, 9, 317. [CrossRef]

32. Freeman, L.C. Centrality in social networks conceptual clarification. Soc. Netw. 1978, 1, 215-239. [CrossRef]

33. Lee, S.H.; Choi, J.Y.; Yoo, S.H.; Oh, Y.G. Evaluating spatial centrality for integrated tourism management in rural areas using GIS and network analysis. Tour. Manag. 2013, 34, 14-24. [CrossRef]

34. Yabe, N. An evaluation of the zoning effects for the regional holiday schedule on travel demand equalization: Finding functional regions by network analysis. Jpn. J. Hum. Geogr. 2013, 65, 264-278. (In Japanese with English Abstract). [CrossRef]

35. Opsahl, T.; Agneessens, F.; Skvoretz, J. Node centrality in weighted networks: Generalizing degree and shortest paths. Soc. Netw. 2010, 32, 245-251. [CrossRef]

36. Gould, R.V. Measures of betweenness in non-symmetric networks. Soc. Netw. 1987, 9, 277-282. [CrossRef]

37. Brin, S.; Page, L. The anatomy of a large-scale hypertextual web search engine. Comput. Netw. Isdn Syst. 1998, 30, 107-117. [CrossRef]

38. Franceschet, M. PageRank: Standing on the shoulders of giants. arXiv, 2010; arXiv:1002.2858. [CrossRef]

39. Sarma, A.D.; Gollapudi, S.; Panigrahy, R. Estimating pagerank on graph streams. JACM 2011, 58, 13. [CrossRef]

(C) 2019 by the authors. Licensee MDPI, Basel, Switzerland. This article is an open access article distributed under the terms and conditions of the Creative Commons Attribution (CC BY) license (http:/ / creativecommons.org/licenses/by/4.0/). 